\title{
In vitro Thrombolytic Activity of Albizia lebbeck Benth.
}

\author{
Saiful Islam Sohaily ${ }^{1}$, Md. Mohidur Rahman ${ }^{1}$, Mohammad Firoz Khan ${ }^{1}$ \\ and Mohammad A. Rashid ${ }^{2}$ \\ ${ }^{1}$ Department of Pharmacy, State University of Bangladesh, Dhaka-1205, Bangladesh \\ ${ }^{2}$ Department of Pharmaceutical Chemistry, University of Dhaka, Dhaka-1000, Bangladesh
}

Received: June 24, 2014;

Accepted: July 21, 2014;

Published (Web): July 23, 2014

The crude methanol extract of bark of Albizia lebbeck Benth. and its Kupchan fractions were screened for thrombolytic activity. Among all partitionates methanol soluble fraction (MESF) of A. lebbeck showed $54.13 \pm$ $0.30 \%$ clot lysis as compared to $66.98 \pm 0.15 \%$ demonstrated by the standard Streptokinase (SK).

A. lebbeck Benth. (Bengali Name- Shirish, Kalo koroi, Family- Fabaceae) is native to Indomalaya, New Guinea and Northern Australia and widely cultivated and naturalised in other tropical and subtropical regions. $A$. lebbeck is an unarmed deciduous tree of $12-21 \mathrm{~m}$ height that grows all over Bangladesh. The bark of $A$. lebbeck is used medicinally to treat inflammation (Lowry et al. 1994). It is an astringent and also used by some cultures to treat boils, cough, eye problems, flu, gingivitis, lung problems and abdominal tumors (Duke, 2008). A. lebbeck is also psychoactive (Ratsch, 2004). Previous phytochemical investigations with $A$. lebbeck revealed the occurrences of glycosides (Varshney, 1976), alkaloids (Dixit and Misra, 1997), terpenoids, steroids, saponins (Pal et al., 1995), anthraquinone and other phenolics (Deshpande and Shastri, 1997) and lupeol, stigmasterol, 4-hydroxy-3-methoxycinnamic, trans-p-coumaric acid (Hussain et al., 2008). Since this plant has important medicinal properties, the present study has been undertaken as part of our regular research program (Amran et al., 2013; Sikder et al., 2013) and we, herein, report thrombolytic activity of the bark of A. lebbeck for the first time.

The bark of A. lebbeck was collected from Chittagong. The collected barks were cut into small pieces, sun dried for several days and then oven dried for 24 hours at $40{ }^{\circ} \mathrm{C}$ to facilitate grinding. The powdered material $(600 \mathrm{~g})$ was extracted with $1.5 \mathrm{~L}$ methanol for 7 days at room temperature and then filtered through a cotton plug followed by Whatman filter paper number 1 . The extract was then concentrated by using a rotary evaporator at reduced temperature $\left(40-45^{\circ} \mathrm{C}\right)$ and pressure. The concetrated methanol extract (ME) was partitionated by the modified Kupchan method (Van Wagenen et al., 1993) and the crude extract along with the resultant patitionates petroleum ether (PE), carbon tetrachloride (CT), and aqueous (AQ) soluble materials were used for screening of thrombolytic activity.

For determining thrombolytic activity blood was drawn from healthy human volunteers without a history of oral contraceptives or anticoagulant therapy and $1.0 \mathrm{ml}$ of venous blood was transferred to the previously weighed microcentrifuge tubes and was allowed to clot.

The thrombolytic activity of all extractives was evaluated by the method developed by Daginawala (2006) using streptokinase (SK) as the standard substance. Commercially available lyophilized Alteplase (Streptokinase) vial (Beacon Pharmaceuticals Ltd.) of 15, 00, $000 \mathrm{IU}$, was collected and $5 \mathrm{ml}$ sterile distilled water was added to it and mixed properly. This suspension was used as a stock from which $100 \mu \mathrm{l}(30,000 \mathrm{IU})$ was used for in vitro thrombolytic studies. The crude extract and each partitionates $(100 \mathrm{mg})$ were suspended in $10 \mathrm{ml}$ of distilled water and it was kept overnight. Then the soluble supernatant was decanted and filtered through a 0.22 micron syringe filter. For clot lysis venous blood drawn from healthy volunteers was distributed in different preweighed sterile microcentrifuge tube $(1 \mathrm{ml} /$ tube $)$ and incubated at $37^{\circ} \mathrm{C}$ for 45 minutes. After clot formation, the serum was completely removed without disturbing the clot and each tube containing the clot was again weighed to determine the weight of clot (clot weight $=$ weight of clot contaning tube - weight of tube alone). 
Then to each microcentrifuge tube with the preweighed clot, $100 \mu \mathrm{l}$ aqueous solutions of different partitionates and crude extract was added separately. Then $100 \mu \mathrm{l}$ of streptokinase and $100 \mu \mathrm{l}$ of distilled water were separately added to the positive and negative control tubes, respectively. All tubes were then incubated at $37^{\circ} \mathrm{C}$ for 90 minutes and observed for lysis of clot, if any. After incubation, the released fluid was removed and tubes were again weighed to observe the difference in weight after clot disruption. Difference obtained in weight taken before and after clot lysis was expressed as percentage of clot lysis as shown below:

$\%$ of clot lysis $=($ wt of clot after release of fluid/clot wt $) \times$ 100

For statistical analysis three replicates of each sample were used for assay and the values are reported as mean \pm SD.

The methanol extract of $A$. lebbeck as well as Kupchan partitionates derived from it were subjected to assay for thrombolytic activity and the results are presented in Table 1. Addition of $100 \mu \mathrm{l} \mathrm{SK}$, a positive control (30,000 IU), to the clots and subsequent incubation for 90 minutes at $37{ }^{\circ} \mathrm{C}$ showed $66.98 \pm 0.15 \%$ lysis of clot. On the other hand, distilled water was treated as negative control produced negligible percentage of lysis of clot. The mean difference in percentage of clot lysis between positive and negative control was found to be statistically significant. In this study, the crude methanol extract (ME) showed highest percentage of clot lysis $(54.13 \pm 0.30 \%)$.

It is clearly evident from the findings that A. lebbeck has thrombolytic activity. Therefore, the plant is a good candidate for further studies to isolate bioactive principles of antithrombotic function for developing new cardioprotective drugs.

Table 1. Thrombolytic activity of A. lebbeck.

\begin{tabular}{lc}
\hline Sample & \% clot lysis \\
\hline ME & $54.13 \pm 0.30$ \\
PE & $22.61 \pm 0.54$ \\
CT & $9.50 \pm 0.65$ \\
AQ & $8.29 \pm 0.20$ \\
Water (Blank) & $5.30 \pm 0.25$ \\
SK & $66.98 \pm 0.15$ \\
\hline
\end{tabular}

$\mathrm{ME}=$ Methanol extract; $\mathrm{PE}=$ Petroleum ether soluble fraction; $\mathrm{CT}=$ Carbon tetrachloride soluble fraction; $\mathrm{AQ}=$ Aqueous soluble fraction; Water $=$ negative control (blank); $\mathrm{SK}=$ Streptokinase (positive control).

\section{References}

Amran, M.S., Sultan, M.Z., Rahman, A. and Rashid, M.A. 2013 Antidiabetic activity of compounds isolated from the Kernel of Mangifera indica in Alloxan induced diabetic rats. Dhaka Univ. J. Pharm. Sci. 12, 77-81.

Duke and James, A. 2008. Dr. Duke's Phytochemical and Ethnobotanical Databases.

Daginawala, H.F., Prasad, S., Kashyap, R.S., Deopujari, J.W., Purohit, H.J. and Taori, G.M. 2006. Development of an in vitro model to study clot lysis activity of thrombolytic Drugs. Thrombosis J. 4, 14

Deshpande, V.H. and Shastri, R.K. 1977. Phenolics of Albizia lebbeck, A. amara and A. procera. Indian J. Chem. 15B, 201-204.

Dixit, A.K. and Misra, L.N. 1997. Macrocyclic budmunchiamine alkaloids from A. lebbeck. Indian J. Nat. Prod. 60, 10361037.

Hussain, M.M., Rahman, M.S., Jabbar, A. and Rashid, M.A. 2008. Phytochemical and biological investigations of Albizzia lebbeck Benth. Bol. Latinoam. Caribe Plant. Med. Aromatics 7, 273-278.

Lowry, J.B., Prinsen, J.H. and Burrows, D.M. 1994. 2.5 Albizia lebbeck - a promising forage tree for semiarid regions, In: Gutteridge, Ross C. \& Shelton, H. Max (eds.): Forage Tree Legumes in Tropical Agriculture.

Pal, B.C., Achari, B., Yoshikawa, K. and Arihara, S. 1995. Saponins from Albizzia lebbek. Phytochemistry. 38, 1287 1291.

Ratsch, Christian, 2004. Enzyklopadie der psychoaktiven Pflanzen, Botanik", Ethnopharmakologie und Anwendungen.

Sikder, M.A, Sharmin, T., Rahman, A. M., Haque, M.R., Rahman, M. S. and Rashid, M.A. 2013. Screenings of four medicinal plants of Bangladesh for bioactivities. Dhaka Univ. J. Pharm. Sci. 12, 59-62.

Vanwagenen, B.C., Larsen, R., Cardellina, J.H., Randazz, D., Lidert, Z.C. and Swithenbank, C. 1993. Ulosantoin, a potent insecticide from the sponge Ulosa ruetzleri. J. Org. Chem. 58, 335-337.

Varshney, I.P. 1976. Glycosides and carbohydrates from the members of the family Leguminosae. Univ. Indore. Res. J. Sci. 4, 13-22. 
